\title{
Geometric morphometric analysis of the molars in three species of the genus Mus (Mus) (Rodentia, Muridae) based on the outline method
}

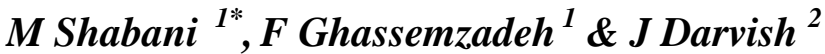

1 Biology Department, Faculty of Sciences, Ferdowsi University of Mashhad, Iran

2 Rodentology Research Department, Faculty of Science, Ferdowsi University of Mashhad, Iran

\begin{abstract}
The relatively new technique of outline-based geometric morphometrics was applied in a study of the variation in the shape of the upper and lower molars among 122 mice, belonging to one species from Iran (Mus musculus) and two species from Europe (Mus macedonicus, Mus spicilegus). Differentiation of specimens based on molar shape was highly dependent on the details of the shape information. Among molars, the second upper and first lower molars are better at separating the species. This method provides a useful way to distinguish species based on the outline of their molars.
\end{abstract}

Keywords: shape variation, upper and lower molars, mice, Iran, Europe.

\section{Introduction}

The ancestor of the genus Mus appeared first in the Indian subcontinent dated to the late Miocene; it has been present in the Mediterranean area from the Middle Pleistocene (Cucchi 2005). Results of a fully resolved tree supports monophyly of the genus Mus, monophyly of the subgenus Mus, and division of the subgenus Mus into Palearctic (M. musculus, M. macedonicus, M. spicilegus, and M. spretus) and Asian (M. cervicolor, M. cookii, and $M$. caroli) clades (Lundrigan et al. 2001). Within the Palaearctic clade, the sister-group relationship between the eastern Mediterranean short-tailed mouse (M. macedonicus) and the mound-building mouse (M. spicilegus) is also well established (Lundrigan et al. 2001, Prager et al. 1996). Mus macedonicus, Mus spretus and Mus spicilegus are therefore closely related to and occur sympatrically with M. musculus in Europe and the Middle East (Suzuki et al. 2004).

Cucchi et al. (2002) demonstrate that M. macedonicus now live on Cyprus and have been there from at least the $9^{\text {th }}$ millenium BC. The steppe mouse, M. spicilegus Petényi, 1882, is presently confined to central Europe (Cucchi 2005), to the European lowlands from Austria and Slovakia in the north, to Bulgaria in the south and the Ukraine in the east, including Serbia, Hungary, Romania, and Moldova (Macholán 1999b).

The house mouse (Mus musculus) is the most recent offshoot of the genus Mus; the native range of the commensal house mice is all of the Eurasia plus North Africa (Prager et al. 1998). It can be divided into three to five taxa that, either as species or subspecies, are designated domesticus of West Europe, North Africa and the Middle East, musculus of eastern Europe and northern Asia, castaneus of southeastern Asia, bactrianus of south-central Asia from Iran to N India (Prager et al. 1998) and the recently designated gentilulus from Yemen.

Several studies have attempted to distinguish these species from each other. For instance, a study of cranial and dental traits tried to distinguish M. musculus and M. spicilegus from other Western Palearctic mouse taxa (Macholán 1996b); and molar shape distinguishes M. spicilegus from European mouse species (Macholán 1996a). Shape analysis is part of geometric morphometrics (Rohlf 2000) that has been quite successful in describing morphological variation.

In this study we looked at the geometric morphometrics of the species M. macedonicus, M. spicilegus and M. musculus using the outline method. The aim of this study is to determine whether variation in the shape of the molars distinguishes these species.

\footnotetext{
* Author for correspondence: tel 009809153071714 email : marjan_shabani_m_64@yahoo.com
} 


\section{Materials \& Methods}

Specimens analyzed in this study came from Iran (house mouse Mus musculus) and Europe (Mus macedonicus, Mus spicilegus). Specimens from Iran were collected from Mashhad

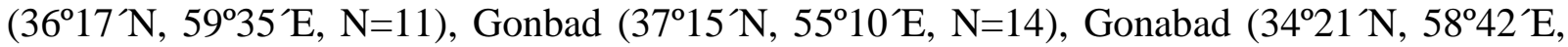
$\mathrm{N}=20)$, Zabol ( $\left.31^{\circ} 2^{\prime} \mathrm{N}, 61^{\circ} 29^{\prime} \mathrm{E}, \mathrm{N}=6\right)$, Birjand ( $\left.32^{\circ} 52^{\prime} \mathrm{N}, 5^{\circ} 12^{\prime} \mathrm{E}, \mathrm{N}=20\right)$, Kerman $\left(30^{\circ} 16^{\prime} \mathrm{N}\right.$, $\left.57^{\circ} 4^{\prime} \mathrm{E}, \mathrm{N}=6\right)$, Shiraz $\left(29^{\circ} 36^{\prime} \mathrm{N}, 5^{\circ} 31^{\prime} \mathrm{E}, \mathrm{N}=8\right)$ and Zanjan $\left(36^{\circ} 40^{\prime} \mathrm{N}, 4^{\circ} 29^{\prime} \mathrm{E}, \mathrm{N}=7\right)$. All samples are deposited in the Rodent Collection of the Zoology Museum of Ferdowsi University, Mashhad, Iran (ZMFUM).

Digital images of the right upper and lower molars of 122 mice were captured using a JVC $^{\text {TM }}$ digital camera connected to an Olympus BH-2 stereomicroscope with objective lens 1 and magnification $2.5 \mathrm{x}$. Images were then organized with tpsUtil version 1.21 (Rohlf 2003) software and recorded using a series of points along the outline of the first and second upper molars (M1/, M2/) and the first lower molar (M/1) with tpsDig v2.12 software. Points were recorded in a sequence beginning at a particular point. Following best practice, we started at an identifiable point: the number of points was 150 points per outline. The program GMTP version 2 (Geometric Morphometric tools package) (Taravati 2009) was used to convert the data from tps format into a format readable for EFAwin (Isaev 1995). The data were then opened and analysed in EFAwin using Fourier decomposition to describe the points using harmonics. The first 15 harmonics were used here as an adequate description of the original data. GMTP then converted the output file of EFAwin to PAST format.

Variation in molar shape among species was assessed by Canonical Discriminant Function Analysis (CDA) based on the harmonic coefficients, using SPSS v15. CDA constructs new axes (one fewer than the number of groups) that maximise the separation of the groups (the between- to the within-group variance), subject to these axes being uncorrelated with one another.

\section{Results}

Fig. 1 shows the results of the CDA for the harmonic coefficients from the first upper molar, displaying the first and second axes, along both of which there is highly significant discrimination among the taxa. The first axis separates $M$. spicilegus from the two other species, and the second axis was effective in separating M. macedonicus from M. musculus (Fig. 1).

The CDA scatterplot for the second upper molar (Fig. 2) showed that each species occupied different areas of the graph. M. musculus was separated along the first axis from the two other species, and the second axis distinguished M. macedonicus and M. spicilegus from each other (Fig. 2).

The CDA for the first lower molar (Fig. 3) once more demonstrated that M. musculus, M. macedonicus and $M$. spicilegus can be separated from each other using molar shape variation. 


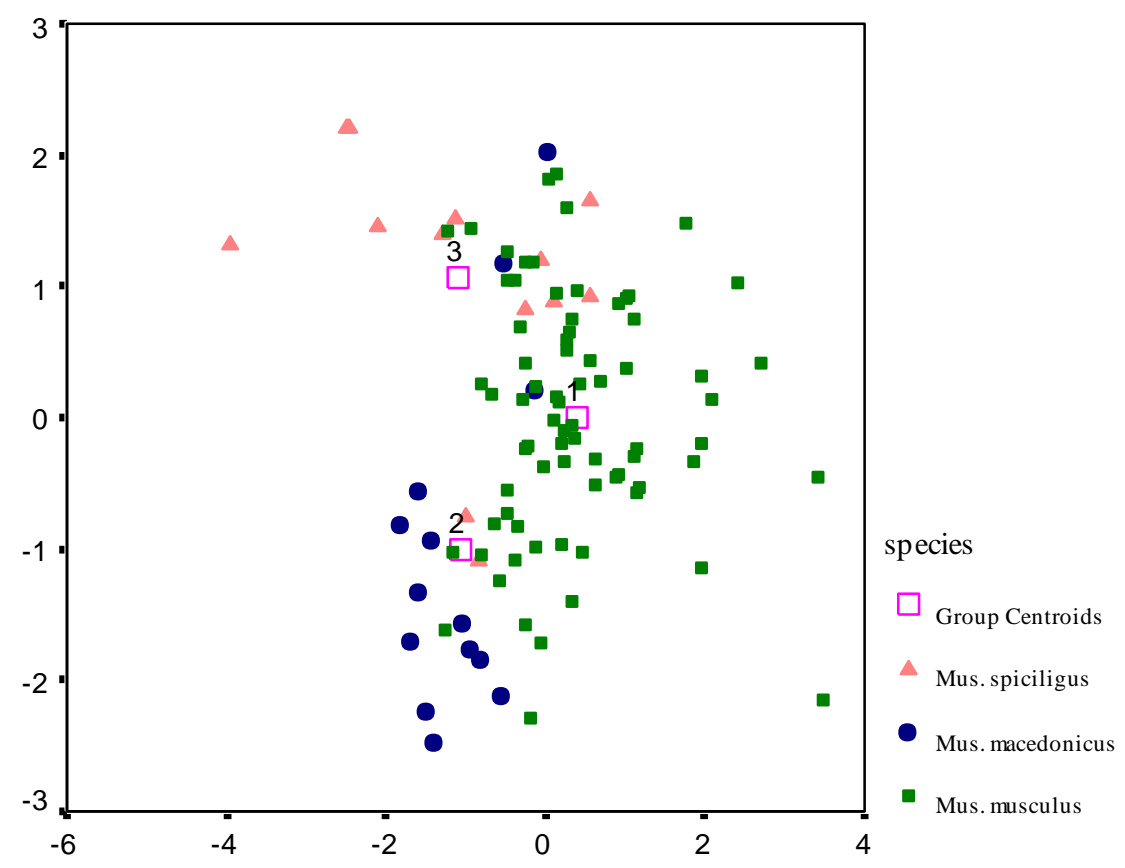

Function 1

Figure 1: Scatter plot of the two axes of the Canonical Discriminant Function Analysis of the outline data for the first upper molar. Together they account for $67 \%$ of the discrimination (Wilks $\lambda=0.231, \mathrm{p}<0.001$ ), and the second axis alone for $32 \%$ (Wilks $\lambda=0.579, \mathrm{p}<0.001$ ).

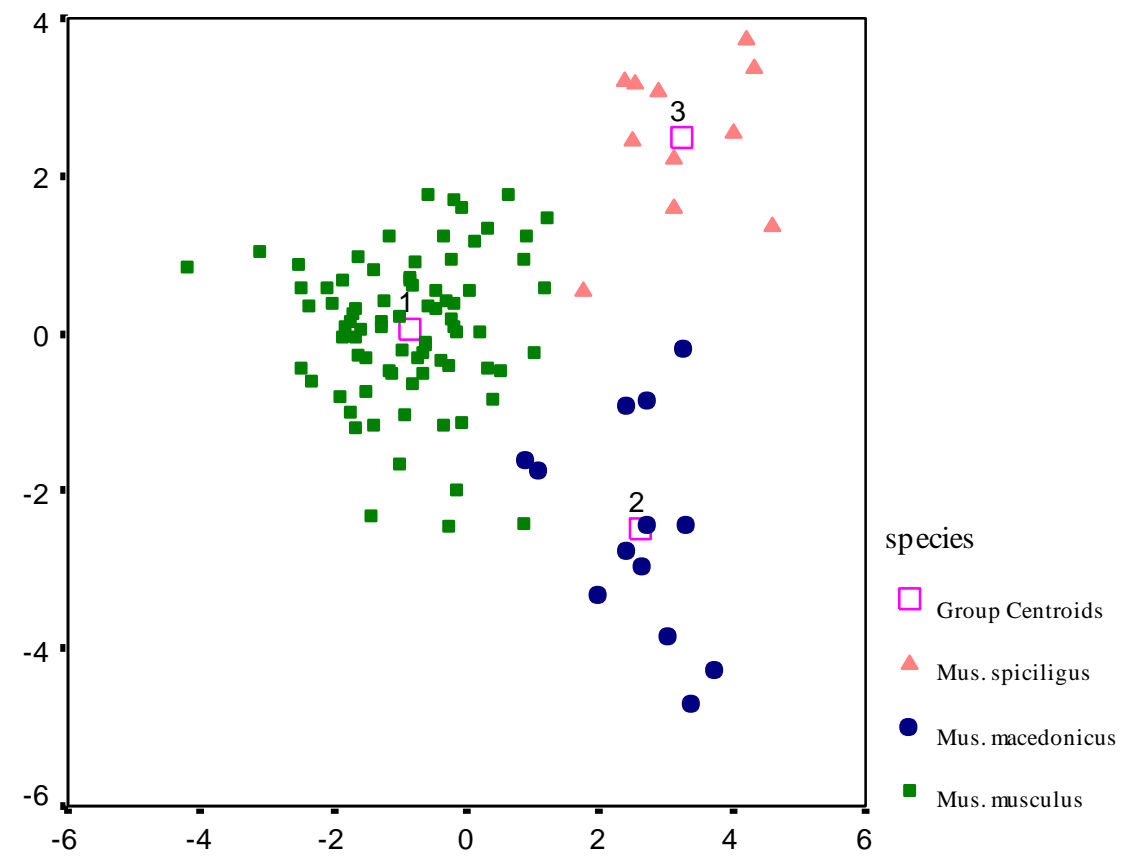

Function 1

Figure 2: Scatter plot of the two axes of the Canonical Discriminant Function Analysis of the outline data for the second upper molar. Together they account for $62 \%$ of the discrimination (Wilks $\lambda=0.113, \mathrm{p}<0.001$ ), and the second axis alone for $36 \%$ (Wilks $\lambda=0.405, \mathrm{p}<0.001$ ). 


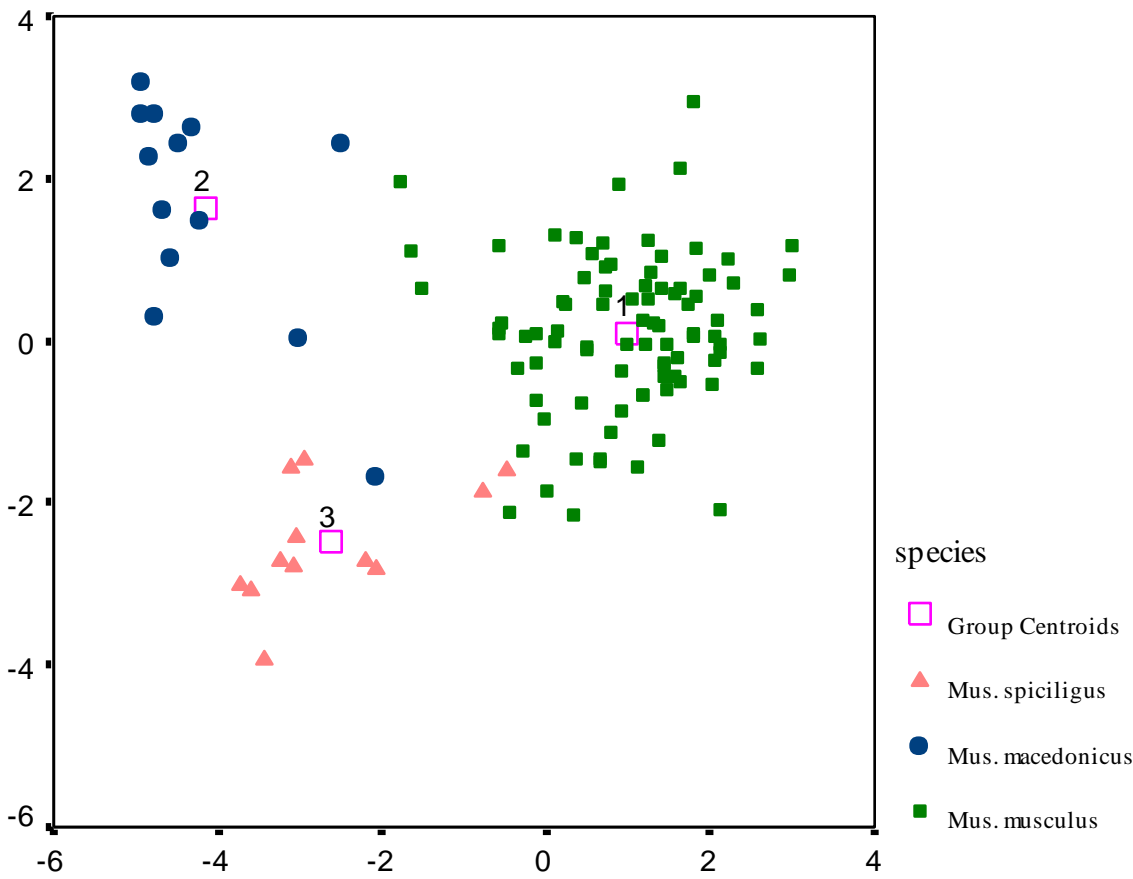

Function 1

Figure 3: Scatter plot of the two axes of the Canonical Discriminant Function Analysis of the outline data for the first lower molar. Together they account for $77 \%$ of the discrimination (Wilks $\lambda=0.110, \mathrm{p}<0.001$ ), and the second axis alone for $22 \%$ (Wilks $\lambda=0.500, \mathrm{p}<0.001$ ).

\section{Discussion}

Discriminating between close species of mice is difficult (Cucchi 2005), but analyzing shape using outlines can be highly effective for interspecific distinctions. In this study we demonstrated that the outline of the molars can be a powerful tool for distinguishing the commensal (M. musculus) from the wild species (M. spicilegus and M. macedonicus), and that this method, as with classical morphometry and morphology, would be an appropriate method for distinguishing among species. House and wild mice can be clearly distinguished based on the shapes of their first and second upper and first lower molars. Therefore, we can conclude that there are significant differences in the molar shapes among M. musculus, M. macedonicus and M. spicilegus. Using the outline method, Cucchi et al. (2002) separated commensal house mice from M. macedonicus using the first lower molar. Among the molars, the first upper molar showed overlap between species (see Fig. 1) probably because variation in the shape of first upper molar is less than that of the second upper and first lower molar.

Several aspects of molar shape are important in the separation of species from each other. For example, tubercle $\mathrm{E}(\mathrm{tE})$ on the anterior lobe of the first lower molar (Orsini 1982) is more developed in M. macedonicus and M. spicilegus than in M. musculus (cf. Fig. 4). In the house mouse the tubercles on the anterior lobe of the first lower molar are more trilobic compared to wild mice. Orsini (1982) used tubercle E on the anterior lobe of the first lower molars to separate the commensal sub-species (M. m. domesticus) from wild species $(M$. spretus and $M$. macedonicus). We suggest that this morphological criterion with variation in the shape of the molar is involved in the separation of the three species studied.

This study focused mainly on the morphology of the teeth. Following this, it is necessary to study geographical and genetic variation of these three species. We could not estimate the effect of geographic and ecological factors on the shape of the molars, because the specimens 
of M. macedonicus and M. spicilegus come from the animal house. However, environmental factors play a major role in dental morphology.

\section{References}

Cserkész T, Gubányi A \& Farkas J (2008) Distinguishing Mus spicilegus from Mus musculus (Rodentia, Muridae) by using cranial measurements. Acta Zoological Academiae Scientiarum Hungaricae 54: 305- 318

Cucchi T, Vigne JD, Auffray JC, P Croft \& Peltenburg E (2002) Passive transport of the house mouse (Mus musculus domesticus) to Cyprus at the Early Preceramic Neolithic (late 9th et $8^{\text {th }}$ millennia BC). Comptes Rendus Palevol 1: 235- 241.

Cucchi T (2005) The passive transportation of the house mouse (Mus musculus domesticus) to Cyprus: New indirect evidence of intensive Neolithic navigation in Eastern Mediterranean. Proceedings of the $6^{\text {th }}$ International Symposium on Archaeozool Southwestern Asia and Adjacent Areas, (ASAAA'05). ARCPublicaties, London, pp 61- 67.

Isaev M (1995) EFA Win Program. Institute of Math Problems of Biology, Moscow Region, Russia (program).

Lundriguan BL, Jansa SA \& Tocker PK (2001) Phylogenetic relationships in the genus Mus, based on paternally, maternally and biparentally inherited characters. Systematic Biology 51(3): 410- 431

Macholán M (1996a) Key to the European house mice (Mus). Folia Zoologica 45: 209 -217

Macholán M ( 1996b) Multivariate morphometric analysis of European species of the genus Mus (Mammalia, Muridae). Zeitschrift fur Saugetierkunde 61: 304 - 319

Macholán M (2006) A geometric morphometric analysis of the shape of the first upper molar in mice of the genus Mus (Muridae, Rodentia). Journal of Zoology 270: 672- 681

Moriwaki K, Shiroishi T \& Yonekawa H (1994) The House Mouse as a Ring Species. pp 13-23 in K Moriwaki, T Shiroishi \& H Yonekawa (eds) Genetics in wild mice its application to biomedical research. Japan Scientific Societies Press, Tokyo.

Orsini P (1982) Factors governing the distribution of mouse in Europe: interests of model mouse for an approach of evolutionary process. PhD Thesis, University of Montellier II.

Orsini P, Bonhomme F, Britton-Davidian J, Croset H, Gerasimov S \& Thaler L (1983) The complex of species of the genus Mus in Central and Eastern Europe. II: Criteria and identifications, distribution and ecology. Zeitschrift für Säugetierkunde 48: 86 -95

Petrov B \& Ruzic A (1982) Preliminary report on the taxonomic status of the members of the genus Mus in Yugoslavia with description of a new subspecies (Mus hortulanus macedonicus ssp.n., Rodentia, Mamm.). Proceedings of the $2^{\text {nd }}$ Symposium on the Serbian Fauna, (SF'83), Beograd, Pp: 175- 178.

Prager EM, Tichy H \& Sage R D (1996) Mitochondrial DNA sequence variation in the eastern house mouse, Mus musculus: comparison with other house mice and report of a 75- bp tandem repeat. Genetics 143: 427-446

Rohlf FJ (2000) On the use of shape spaces to compare morphometric methods. Hystrix 11: 9- 25

Rohlf FJ (2003) TPSutil-TPS Utility Program. Stony Brook University New York.

Suzuki H, Shimada T, Terashima M, Tsuchiya K \& Aplin K (2004) Temporal, spatial, and ecological modes of evolution of Eurasian Mus based on mitochondrial and nuclear gene sequences. Molecular Phylogenetics \& Evolution 33: 626-646

Taravati S (2009) Geometric Morphometric Tools Package (GMTP program). Rodents Research Department of Ferdowsi University of Mashhad.

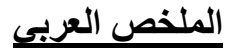

التحاليل الهندسية و المظهرية لضروس ثلاثة أنو اع من تحت جنس Mus (Rodentia, Muridae) باستخدام طريقة

الخطوط العريضة الخينة

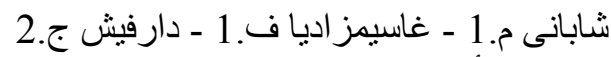

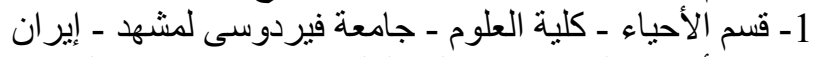

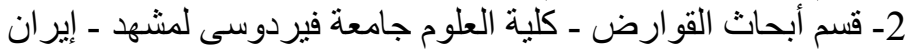

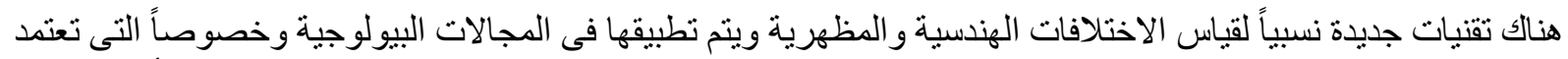

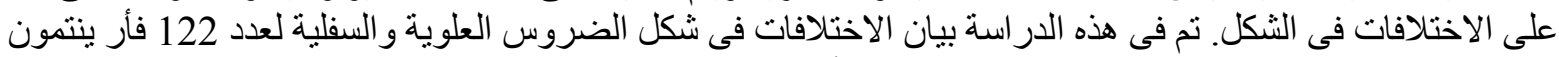

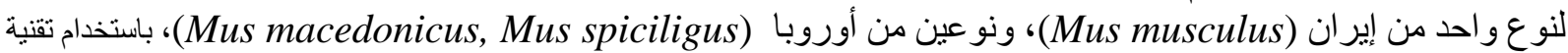

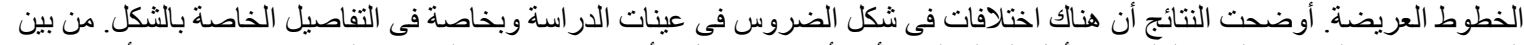

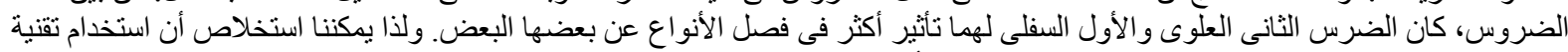
الخطوط العريضة للضروس تمدنا بطريقة مفيدة فى تمييز الأنواع. 